\title{
Real (and) Imaginal Relationships with the Dead
}

\author{
Kathryn J. Norlock ${ }^{1}$
}

Published online: 19 November 2016

(C) The Author(s) 2016. This article is published with open access at Springerlink.com

Although philosophers have written much about death, appreciating the nature and the value of the relationship of the living to our dead is an aspect of human life that we seem to have neglected. ${ }^{1}$ Like many feminist ethicists, I have argued explicitly for the value of relationships simpliciter, especially from the perspective of the ethics of care; I am influenced by philosophers including Virginia Held, who says that "to the ethics of care, our embeddedness in familial, social, and historical contexts is basic,"2 and Diana Meyers, who describes the relational self as "the interpersonally bonded self," for whom "relationships are sources of moral identity." 3 And some metaphysicians have analyzed the ontology of dead persons as relata, including Niall Connelly and Palle Yourgrau, whose accounts I rely on in this

\footnotetext{
${ }^{1}$ Notable exceptions in philosophy include Matthew Ratcliffe, "Relating to the Dead: Social Cognition and the Phenomenology of Grief," in Phenomenology of Sociality: Discovering the 'We,' eds. Thomas Szanto and Dermot Moran (New York: Routledge, 2016), pp. 202-215, and in a distinctive and different way, Michelle Ballif, "Regarding the Dead," Philosophy and Rhetoric, vol. 47, no. 4, 2014, pp. 455-471. It is difficult to find appreciation of relationship with the dead in works that rely on traditionally analytic sources, perhaps because traditionally analytical philosophers have been slow to attend to relational values; recent examples include Stephen Haller, "Grave Concerns: Concepts of Self and Respect for the Dead," International Journal of Applied Philosophy, vol. 21, no. 2, 2008, pp. 195-212, and J. Jeremy Wisnewski, "What We Owe the Dead," Journal of Applied Philosophy, vol. 26, no. 1, 2009, pp. 54-70. One can find a number of further articles that take up the nature of deceased persons, even duties to the dead, but rarely are relationships between the living and the dead a focus or driving concern of such treatments.

2 Virginia Held, The Ethics of Care: Personal, Political, and Global (Oxford: Oxford University Press, 2006), p. 46.

3 Diana Tietjens Meyers, "Narrative and Moral Life," in Setting the Moral Compass, ed. Cheshire Calhoun (New York: Oxford University Press, 2004), p. 292.
}

Kathryn J. Norlock

kathrynnorlock@trentu.ca

1 Department of Philosophy, Trent University, 1600 West Bank Drive, Peterborough, ON K9L 0G2, Canada 
essay and who argue that the dead stand in real, not merely imaginary, relationships to the living; as Yourgrau states, "Talk of the dead is of an entirely different order from, say, talk of the tooth fairy," and he energetically rejects the idea that the dead, once gone, are merely memories and impressions. ${ }^{4}$ Yet it is difficult to find work interrelating the efforts of metaphysicians and ethicists, especially when attempting to settle questions in ethics, such as whether one can forgive the dead, or whether one must respect the wishes of the dead or honor their memories. ${ }^{5}$

Obstacles to interrelating such accounts may include the commitments of some ethical theorists to focus on reciprocity or mutuality; Nel Noddings, for example, emphasizes that "there is, necessarily, a form of reciprocity in caring," and approvingly cites Martin Buber's statement that "relation is reciprocity."6 Relatedly, Kim Atkins argues against the possibility of forgiving the dead, on the grounds that relationships entail something like Aristotelian friendship, "mutuality rather than something brought about solely by the action of an individual." 7 In this essay, I am sympathetic to relational accounts of moral processes as more than the internal mental representations of an individual. I agree that moral relationships and personal relationships are meaningful things that exceed individualistic accounts of intentional actions or internal thoughts. However, as I show in what follows, I am persuaded by work in metaphysics, work in philosophy of memory as advanced by Sue Campbell, and work in philosophical and psychological literature on bereavement, that the relationships bereaved persons may maintain with the dead are meaningful even when they are no longer reciprocal, and not merely limited to past impressions. As philosopher Matthew Ratcliffe argues eloquently, "The sense of being rooted in a meaningful world depends not just upon an isolated self and its projects but upon relations with particular others," and some experiences of grief at the absence of those with whom one's relationship was meaningful "may continue to be experienced as mattering in the ways they do in the light of how one once related to $\mathrm{S}$ and, indeed, how one continues to think about and relate to S." 8 Helpfully for my purposes, Ratcliffe observes, "One might think... that full acknowledgement of S's absence implies the impossibility of relating to him. But, interestingly, some narratives of grief suggest otherwise." 9 This paper endeavours

\footnotetext{
4 Palle Yourgrau, "The Dead," The Journal of Philosophy, vol. 84, no. 2, 1987, p. 86.

5 Of course, one can find philosophical work from ancient philosophy right up to the present regarding whether or not the dead can be harmed or happy, but most such work assesses more individualistic considerations such as whether a dead person has rights against others, interests that can be harmed, or a trustee obligated to carry out fiduciary duties. My concerns are rather more focused on how and whether we survivors think about our relationships to those who have died, an aspect of moral life not generally discussed in the literature on the harm or happiness of the dead.

${ }^{6}$ Nel Noddings, Caring: A Relational Approach to Ethics and Moral Education, $2^{\text {nd }}$ ed, updated (Berkeley and Los Angeles: University of California Press, 2013), p. 71, p. 73; Martin Buber, I and Thou, trans. Walter Kaufmann (New York: Charles Scribner's Sons, 1970), p. 60.

7 Kim Atkins, "Friendship, Trust, and Forgiveness," Philosophia, vol. 29, no. 1, 2002, p. 111. More recently, Charles Griswold observes that in the "ideal context, forgiveness requires reciprocity;" although he later sketches an account of forgiving the dead in nonideal situations, he does not.

8 Ratcliffe, "Relating to the Dead," p. 206, 207.

9 Ibid., p. 210.
} 
to provide philosophers further reasons to reject impossibility with respect to relationships between the living and the dead.

Accounts of the sorts of relationships in which I am interested bear some similarities to what some bereavement counselors call imaginal relationships with the dead. The concept of imaginal relationships ought to be more familiar to philosophers who deliberate about relationships between the living, as well. An understanding that some, and not all, imaginal relationships are merely imaginary while some, and not all, imaginal relationships are continuous with relationships of reciprocity better informs descriptive accounts of relationships that matter to us personally, and provides clearer meta-ethical bases for philosophers' ethical recommendations with respect to our dead. ${ }^{10}$ Whether and when to tell your children about your deceased abusive parent, whether and how to write to the surviving kin of an acquaintance who died, and how and why to forgive one's deceased wrongdoer, raise complex questions as to what it means to have a relationship at all. In this essay, I advocate attention to psychologists' conceptual analyses of imaginal relationships in order to clarify that relationships between living entities include imaginal content that endows our relationships with moral import and meaningfulness, and therefore, relationships can continue after one of the relata has died, when the survivor continues to relate to the dead in imaginal ways. Real relationships are not limited to those of reciprocity between the living.

It is important that philosophers affirm, more clearly than we have, that for metaethical and ethical reasons we can maintain ongoing, meaningful, valuable relationships with deceased others. I suggest that attending to psychologists' insights regarding imaginal relationships with our dead assists in the project that ethicists should pursue of ascertaining the nature of relationships. Arguments for imaginal relationships better generate claims in applied ethics about our conduct with respect to our dead. In the first half of this paper, I advance the more modest claim that psychological literature affirmative of imaginal relationships with the dead is relevant to philosophical literature on metaphysical arguments for the dead as relata. ${ }^{11}$ I do so with the aim of demonstrating that at times we do not merely remember the dead, we actively relate to the deceased because we are maintaining a relationship that we had with them while living; therefore, fulfilling the wishes of

\footnotetext{
10 As I explain in more detail in the essay, imaginal relationships can include imaginary relationships, but are intended to describe a wider set, of which imaginary relationships are only a subset.

${ }^{11}$ It is out of the scope of the current paper to give a thorough account of what metaphysical commitments to the nature of time I am espousing. I content myself with the observation that Niall Connelly's variety of Meinongian Presentism, in his work cited in this paper, is supportive of and compatible with my account; "the view that only the present is real," and that Socrates does not exist the same way that (Connelly's example) currently Australians exist, "denies, not implausibly, that individuals that no longer exist have the same ontological status as Australians. Socrates, assuming the truth of Presentism, categorically doesn't exist. But there are reasons to stop short of saying that there is no such thing as Socrates. The first reason is that we stand in relations to Socrates (if to love, or to think about, or to refer to, is to stand in a relation to an 'intentional object'). The second reason is that there are truths like: 'Socrates was a philosopher'-truths that capture what Socrates was like when he existed." Niall Connolly, "How the Dead Live," Philosophia, vol. 39, no. 1, 2011, p. 84. Having said that, I take my view to be compatible with many metaphysical accounts of the nature of time, and even if one is an Eternalist or adheres to Special Relativity, it just is the case that it is sensible to say the sentence, "John Rawls argues against my view."
} 
the dead or forgiving the dead are properly beheld to be imaginal aspects of an ongoing relationship.

My more ambitious aim in the second half of this paper is to show that the importance of one's most dearly held relationships with living individuals is best explained in terms of imaginal content, as well; in other words, some interpersonal relationships between the living are personally important because of their imaginal content. Once we appreciate this, it is clearer why recognizably real, mutual, imaginally informed relationships with the living are not necessarily cut off on the day someone dies, because what we hold to be valuable and meaningful about our relationships includes the results of our mutual interactions, and not merely the mutual interactions in themselves. The imaginal content of meaningful relationships includes our reflections on the value of our interactions, our commitments resulting from our interactions, and our beliefs about ourselves as we are shaped by our interactions. Therefore, death in itself is not necessarily an obstacle to continuing the imaginal relationships that one may already have with living loved ones.

The account I build of real and imaginal relationships that survivors maintain with the deceased is intended to describe somewhat overlooked qualities of one's actual, meaningful interpersonal relationships, but in Part Two I further consider the possible objections that such an account is too accommodating of wishful thinking. I consider the possible objection from a skeptical philosopher that not all imaginal relationships turn out to be 'real' relationships in the ways that matter to assessing ethical behavior in relationships. For example, some parasocial (that is, one-sided) relationships, such as might be built up by a celebrity stalker, a castaway who talks to a volleyball, and a girl who cares for a rag doll, are all possible examples of imaginal relationships that the skeptic might argue are not real, in part because they are not reciprocal even if they seem so to the agent who constructed the relationship in his or her head. This may suggest that imaginal relationships with the dead are likewise not-real because parasocial, but I conclude that the possible counterexamples help my argument more than they problematize it. As I describe them, the sets of imaginal relationships and not-merely-imaginary relationships overlap, and appreciating the reasons for their overlap better enables philosophers of relational ethics to explicate the functions of relational and ethical practices such as respecting the wishes of the dead, honoring the memory of the dead, and forgiving the dead. Much of what it means for a relationship to be more than merely imaginary, to be predicated on past reciprocity or responsive activities, will turn on the material facts of the memories and interactions that support the imaginal content, including previous reciprocity or mutuality in a relationship.

It is an empirical difficulty, but not a metaphysical obstacle, that outsiders' assessments of the nature of a relationship depend upon their view of the authority of the relationship-maintainer with respect to the facts about the object of their love. I occasionally say with affection, when I do something odd to acquaintances but familiar to me because it is exactly as one of my parents does it, "Yes, I sure take after my father," or, "I really am turning into my mother." One must take my word for it on such occasions. If we grant that I have good bases for perceiving my similarity to a parent, then my larger point remains that my observation seems true today, and it will still seem true if I say it on the day the parent dies, or the day after 
that. One upshot of this paper may be that I end up committed to a view that death can possibly be irrelevant to some continued relationships, depending on what is required for them to continue. That is a bullet I am prepared to bite.

\section{Imaginal Relationships with the Dead}

Perhaps many readers have had the experience of not just thinking about a dead friend or family member, but holding an inner dialogue or argument with the departed individual, or imagining their responses to one's actions or beliefs, or maintaining a practice previously shared with the deceased because it was shared with the deceased. In doing so, a living person may be said to maintain a relationship with a deceased person. Some philosophers might resist this, on the grounds that, even if the dead were relata when living, the meaningful, actual relationship one had to an individual who lived ended when the individual died, and therefore a deceased person cannot be a relata in a particular, personal relationship. On that view, dead people are not relata, and relationships with them are not "real" relationships. ${ }^{12}$ They are merely memories, and one's inner dialogues mere fancies.

Although they rarely cite each other, both psychologists and philosophers have advanced reasons to reject the view of relationships with dead individuals as merely metaphorical, or dispositions toward dead relata as merely fanciful. To provide a sketch of arguments in both traditions and demonstrate their relevance to each other, I turn first to the scholarship of psychologists and bereavement scholars regarding imaginal relationships, defined below. I relate their account of imaginal relationships with the dead to the work of philosopher Sue Campbell on the ongoing processes involved in remembering one's dead, and Niall Connolly and Palle Yourgrau on the metaphysics of dead non-/entities. I argue that ongoing activities of remembering and imagination inform the real relationship; in short, just because a relationship with the dead is imaginal, doesn't mean it isn't very real.

Psychologists demonstrate an interest in the therapeutic benefits to bereaved individuals of imaginal relationships with the dead ${ }^{13}$; the very presence of arguments for therapeutic benefits may be a reason for some skeptical philosophers to discount the possibility that the relationship has any metaphysical reality. Although philosophers have good reasons to be suspicious of inferring a thing's existence from the good feelings that result from thinking it exists, I plea the reader's patience and ask only that skeptics of good feeling suspend their usual

\footnotetext{
12 My thanks to Baruch Brody for stating exactly this wording in his objection, and for our helpful discussion of it; Baruch Brody, personal communication, October 16, 2015.

13 Evidence includes the works of Sandra M. Dannenbaum and Richard T. Kinnier, "Imaginal Relationships With the Dead: Applications for Psychotherapy," Journal of Humanistic Psychology, vol. 49, no. 1, 2009; Continuing Bonds: New Understandings of Grief, edited by Dennis Klass, Phyllis R. Silverman, and Steven L. Nickman (New York and London: Routledge, 1996); Robert A. Neimeyer, Scott A. Baldwin, and James Gillies. "Continuing bonds and reconstructing meaning: Mitigating complications in bereavement," Death studies 30, no. 8 (2006), pp. 715-738; Robert A. Neimeyer "Reauthoring life narratives: Grief therapy as meaning reconstruction," The Israel Journal of Psychiatry and Related Sciences 38, no. 3/4 (2001), p. 171; Margaret Stroebe \& Wolfgang Stroebe, "Does 'grief work' work?" Journal of Consulting and Clinical Psychology, 59 (1991), pp. 479-482.
} 
suspicions. Psychologists may be motivated by their duty to attend to therapeutically beneficial practices, but the reverse argument also holds that from a practice's good consequences, one is not yet justified in inferring that the results are the product of delusion.

Psychological work on imaginal relationships has been most concertedly developed in the past twenty years; the consensus appears to be that imaginal relationships are both therapeutically beneficial and the product of actual experiences, although some authors suggest that controversy remains as to whether all imaginal relationships are imaginary, even pathological. ${ }^{14}$ Mary Watkins is credited with early "use of the word imaginal in preference to imagined or imaginary." 15 As Mary Gergen states, in her endorsement of Watkins' account, "Whereas the latter two words suggest something fictional or frivolous, imaginal suggests other, more consequential possibilities." 16 Watkins develops a detailed account of imaginal dialogues as entailing imaginative development; arguing that the imagination is derivative of and helpful to the real, she appeals to George Herbert Mead's view that imaginal dialogues are constitutive of reason. ${ }^{17}$ Watkins advocates a Meadian view that self-awareness includes robust appreciation of how others see us, and Watkins persuasively establishes that the imaginal work of adding interpretive content to what one perceives or knows about others' perceptions is not contrary to rational thought, but actually in service of rationality, and not imaginary, but developed imaginally on the basis of known actualities.

\footnotetext{
${ }^{14}$ Edith Steffen and Adrian Coyle describe the shift away from "clinical interest in psychoanalyticallyorientated 'grief work' conducted in psychiatric practice in which the practitioner's concern is to help the bereaved patient 'let go' of the deceased and "move on," and they explicitly note the expansion of interest in the past 20 years in particular: "Openly opposing the so-called 'breaking bonds' paradigm of the psychoanalytical tradition, the publication of the edited volume Continuing Bonds: New Understandings of Grief by Klass, Silverman and Nickman in 1996 led to a much-documented paradigm-shift in bereavement research." Edith Steffen and Adrian Coyle, “'Sense of presence' experiences in bereavement and their relationship to mental health: A critical examination of a continuing controversy," in C. Murray (Ed.), Mental health and anomalous experience (Hauppauge, NY: Nova Science Publishers, 2012), p. 34. Steffen and Coyle further note that the development of psychological literature continued to include controversy, for some; "While a conceptualisation of these experiences as 'hallucinatory' was maintained, researchers increasingly drew attention to their widespread prevalence and consoling effect on the bereaved and started to question the pathology label that had hitherto been applied to the experience." (Ibid.) These observations are shared by Jeanne Rothaupt and Kent Becker, who write, "Prior to this new wave of grief research, it was generally accepted by researchers and clinicians that to recover from bereavement a person needed to do their grief work ... Overall, the idea of grief work includes the need to confront the reality that the loved one had died, to go over the memories and possible trauma prior to and immediately after the death, and finally to work toward emotional detachment of the deceased... The ultimate goal of breaking emotional bonds with the deceased is changing in grief research circles." Jeanne W. Rothaupt and Kent Becker, "A Literature Review of Western Bereavement Theory: From Decathecting to Continuing Bonds," The Family Journal: Counseling and Therapy for Couples and Families, Vol. 15 No. 1, January 2007, pp. 6-15.

15 This point about Watkins' work is developed by Mary Gergen, Feminist Reconstructions in Psychology: Narrative, Gender, and Performance (Thousand Oaks, Cal.: Sage Publications, 2001), p. 144 n3.

16 Ibid.

${ }^{17}$ Mary Watkins, Invisible guests: The development of imaginal dialogues (Hillsdale, N.J.: The Analytic Press, Inc., 1986), p. 32, p. 18.
} 
If anything, it is more rational to imaginatively interpret the indicators of others as to what they think of oneself than it is to proceed as though one cannot imagine what anyone thinks. Just in the course of writing this paper, I have considered the questions of recent interlocutors, and done the imaginal work of considering why their questions took the form they did, and how they might respond to my responses. I carry on an internal dialogue in the course of reasoning my way to a more accurate essay. To refer to our internal dialogues when writing philosophy as 'imaginary' dialogues would connote something more unhooked from material realities than our writing processes actually are. Watkins' offer of the term 'imaginal dialogue' captures better the sense that our dialogical thinking processes are not fictional creations so much as interpretive narratives based on experiences with real persons. The internal dialogues of philosophical writers may involve creative thinking, but we wouldn't describe the results as fictions. After all, we're trying to get something right. It is more appropriate to describe our internal dialogues as involving imaginal content.

Drawing on Watkins' conception of the imaginal dialogue, psychologists including Gergen have developed arguments for imaginal relationships with deceased loved ones as continued bonds maintained by the living, especially through imaginal content. Maintaining relationships with deceased others, on Gergen's view, can include imaginal dialogues with the dead, considering what they would think of one's behavior, identifying with the deceased, and carrying out the wishes that they may have expressed or that one comes to think they would have had. "To talk, laugh, and wonder, to be surprised, upset, hurt, angry, and amused, and to engage in other physical acts could all be a part of imaginal interactions," Gergen adds. ${ }^{18}$ Sandra Dannenbaum and Richard Kinnier include forms of maintenance such as addressing the deceased as comforting confidants, taking them as role models, using their tools in one's own work, and even acting in one's own job as a deceased parent acted in a similar job. They add, "The experience [of cultivation of relationships with the dead] also provided some with a fuller sense of familial connection between generations." ${ }^{19}$ They cite the example of a respondent who emphasized the personal importance of "the legacy of these deceased persons (whether it be family recipes, moral codes, behavioral expectations, etc.)," suggesting that one's imaginal relationships both inform and are informed by one's behaviors in the external world. ${ }^{20}$

Imaginal conversations are a major method of maintaining imaginal relationships in most accounts, but not the sole means. Bereaved individuals report ongoing feelings of closeness with the dead, either cultivated or involuntary senses of a deceased individual's presence, and activities including (either deliberate or involuntary) verbal address to the dead, visiting gravesites and previously frequented places, intentionally using possessions that belonged to deceased loved ones, and other means and sources of connection. As I address below, it is still the

\footnotetext{
18 Gergen, Feminist Reconstructions in Psychology, p. 125.

19 Sandra M. Dannenbaum and Richard T. Kinnier, "Imaginal Relationships With the Dead: Applications for Psychotherapy," Journal of Humanistic Psychology, vol. 49, no. 1, 2009, p. 107.

20 Ibid.
} 
case that not all psychologists agree as to which perceptions of closeness following bereavement are therapeutic, helpful, hallucinatory, even harmful. It is less debatable in the literature that, when done well and with the help of supportive others, imaginal relationships are promoting of mental health and well-being.

I should add that psychologists have not always been so splendid about acknowledging the real and/or ongoing relationships some bereaved persons maintain with dead loved ones. Although the past twenty years seems to have brought about a consensus among psychologists that some bereaved persons' perceptions of closeness are healthy, normal, to be cultivated at least temporarily, and not necessarily to be let go, much of 20th-century bereavement counseling was dedicated to ending or eradicating these sorts of imaginal relationships the living can have with the dead. As Stroebe et al. explain, "The belief in the importance of severing ties from a deceased loved one found early and important expression in Freud's work." 21 Scott Becker and Roger Knudson identify "the traditional psychoanalytic presupposition that successful mourning requires an emotional detachment (decathexis) from the deceased." 22 The view that bonds must be broken and death must be gotten over, they add, "has largely been replaced in contemporary grief research by the recognition that mourners often remain connected to the deceased, and that this attachment is not inherently pathological or maladaptive." ${ }^{23}$ They identify a consensus among counselors "that the mourner often finds a constructive way of maintaining a meaningful relationship to the deceased through private memories, public memorials, secular and religious rituals, and spiritual beliefs." 24 Similarly, Marilyn McCabe points out that until recently, theorists approached grief as a phase or stage of internal and isolatable feeling that can and should be got over. She notes the past predominance of focus on "a definitive ending and a definitive place the deceased can be for the bereaved," that is, firmly fixed in the past. ${ }^{25}$ She adds, "This emphasis ignores any kind of dynamic, ongoing, imaginative, and emotional process, except to label it as pathological." 26

McCabe's criticism of much phase theory is reminiscent of philosopher Sue Campbell's account of the "older storehouse model of memory" as archived in a particular location in the brain in response to events. ${ }^{27}$ Campbell says, "The storehouse model represents memories as not only caused by the past, but as singular and stable in meaning... Historically, unstable, shifting, gappy, or contradictory memories have been taken to indicate the presence of a disturbed

\footnotetext{
21 Margaret Stroebe, Mary Gergen, Kenneth Gergen, and Wolfgang Stroebe, "Broken Hearts or Broken Bonds?", in Continuing Bonds: New Understandings of Grief, p. 33.

22 Scott H. Becker and Roger M. Knudson, "Visions of the Dead: Imagination and Mourning," Death Studies, vol. 27, no. 8, p. 691.

23 Ibid.

24 Ibid., p. 692.

25 Marilyn McCabe, The Paradox Of Loss: Toward A Relational Theory Of Grief (New York: Praeger, 2003), p. 39.

26 Ibid.

27 Sue Campbell, Our Faithfulness to the Past: The Ethics and Politics of Memory (Oxford: Oxford University Press, 2014), p. 53.
} 
self, of fragmentation, dissociation, or other psychopathology." ${ }^{28}$ The reflection or rumination of a survivor on the memories of their dead can be especially opposed by storehouse-adherents as upsetting, when one should be burying the dead literally and mentally in the past. Campbell endorses, in contrast to the storehouse model, a reconstructive account of memory, holding among other things that we "remember from the context of our present needs and interests." 29 In both psychological accounts of imaginal relationships, and Campbell's philosophical account of reconstructive memory, one finds the authors assuming the burden of proof against traditional assumptions that it is pathological to reconstitute memory in order to serve our present needs and interests. Campbell urges philosophers' sensitivity to those who have suffered harms and losses including bereavement, arguing for trust in victims' perceptions and moral deference on the part of witnesses. ${ }^{30}$

The language of reconstructive memory is present in McCabe's description of her own experience of grieving her mother, one involving "self-nurturing" activities that included "reminiscing and re-evoking Ruthy's words and shoring up the relationship... It is an imaginal co-construction in that I actively call upon my memories of Ruthy...created in the form of a self-dialogue." ${ }^{31}$ She concludes, "The relationship with the lost one, which is not relinquished but instead, continues to be reconstituted,... [is] based both on fact" - this person existed, they said such things - "and fantasy" - insofar as some imaginative work is done in one's internal dialogues and association of activities with the lost one - "but it is the fact that the other was real and lives no more" that makes bereaved persons' imaginal relationship non-fantasy. "The very real absence," McCabe says, "contributes to the internalized presence." 33

Of course, the skeptical philosopher may be very sympathetic to McCabe's account of grief and happily grant that dialogical-selves engage in healthy selfnurturing through imaginal activities, while still maintaining that real relationships are only those relationships between at least two living individuals which are acknowledged and in some way consciously maintained by each relata. On this view, it's not that there's no important imaginal activity going on, it's just that relationship with the dead is imaginal and not real. One might object that only living entities are relata, because only the living can be entities. This has been disputed by philosophers including Niall Connolly and Palle Yourgrau; as Connolly argues in "How the Dead Live," the dead are sensible objects of statements of relationship; he argues for seeing dead persons as "non-existent objects." 34

The living stand in relations to the dead. This is part of the case I want to make for the thesis that the dead are examples of non-existent objects. Some of the

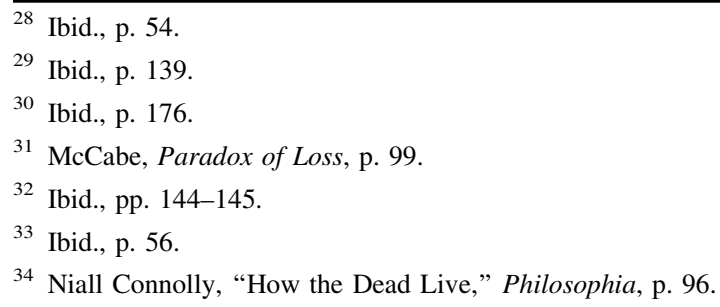


facts involving the dead are facts about the relations they stand in to the living. ${ }^{35}$

To say today, for example, that Claudia Card was a philosopher, is to say something about the present in relation to a person who actually lived and died. The arguments on the part of Connelly and Yourgrau, that one can sensibly say "I remember Claudia fondly" because Claudia was a person who lived, are remarkably consonant with McCabe's emphasis on "the fact that the other was real and lives no more." As Connolly says, citing Quine, a statement like this is importantly different from the statement, "Pegasus is a winged horse." Connolly adds, "A pedant, or someone taken to task for suggesting that there are winged horses, will resort to the paraphrase 'according to the myth, Pegasus is a winged horse.' Nobody would feel a similar need to paraphrase" the statement that a philosopher lived and died. ${ }^{36}$ Connolly argues that if the dead are nonexistent objects, then we can offer claims about relationships with them: "Yourgrau's defense of the dead as examples of nonexistent objects invokes the relations the living stand in to the dead. John loves Socrates. John's love is a relation between him and Socrates. A relation is instantiated only if its relata count among the things there are. So there is such a thing as Socrates." 37

As Yourgrau says, “There is, [in] Quine's sense, a 'notional' kind of love, which we can feel even for Pegasus. But there is also, clearly, a 'relational sense' of 'love' according to which it is the object itself that we love; and how could one be expected to maintain this relationship when one of the terms is missing?" 38 One might object that Yourgrau and Connolly arguably rely on common-language statements of relationship to justify the metaphysics of the dead as relata, a potentially circular argument. Yourgrau admittedly does state the motivation of preserving our intuitions, but defends the notion of dead relata as nonexistent objects using language remarkably similar to McCabe's in accounting for the nonfantastical relationship she maintains with her mother; he points to the material fact that dead persons were specific and actual, unlike fictional creations. "Just as we are intimate with various existent objects, we, most of us, are familiar with specific past objects (those we know who have died), and we are all used to dealing with the future. If we but let our eyes be opened, we will see that we have all along been trafficking with the nonexistent, as with the existent." ${ }^{39}$ For McCabe and Yourgrau, as with the theorists above, epistemological stakes hold in place the metaphysics of nonexistent objects and imaginal relationships. "The dead, for example, are a set of nonexistents easier to grasp than the unborn. We can name specific dead people and we know many detailed facts about them," Yourgrau points out. ${ }^{40}$ (I turn my attention to an example involving the unborn in Part Two.)

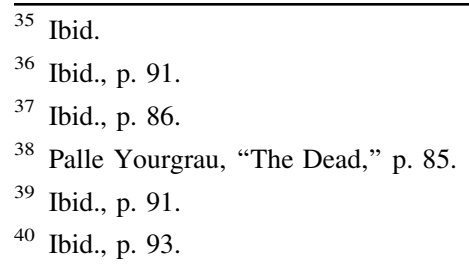


Connolly and Yourgrau are largely occupied with establishing a bare metaphysical claim, that statements about one's disposition toward the dead are relational with respect to objects and their qualities, and not merely statements about internal qualities of one's own thoughts. I rely on their efforts here because I believe that normative arguments on the part of psychologists, that the bereaved should be affirmed and not pathologized in their imaginal relationships, are provided with metaphysical bases when connected to the work of philosophers who point out that the dead are proper objects after they cease to exist. I maintain that bereaved persons have not just feelings and beliefs about the dead, but continue to uphold relationships of a sort with the dead, and in light of the explorations in Part Two below, I offer reasons in my conclusion for seeing these as real, meaningful, imaginal relationships. I can still imagine skeptical philosophers holding out. Perhaps the relata are (not just 'were') real, and perhaps one is engaged in objecttargeted imaginal activity, but relata plus imaginal content can result in a real relationship between a castaway and a volleyball, or a real relationship between a celebrity and a stalker. Are these real, meaningful, even loving relationships? The implications of taking imaginal relationships as informative of real relationships with the living or the dead are the subject of the second half of this essay.

\section{Imaginal Relationships with the Living}

In working out whether an imaginal relationship with the dead is real, I have found it helpful to reflect on a possibility neglected at the other end of the spectrum, that is, the possibility that some relationships are more real than imaginal, such as the relationship between twin infant humans. Baby twins can be living entities in an interpersonal, perhaps even intimate and proximate relationship, yet we would understandably hesitate to say that the babies engage in the sort of robustly intentional, imaginal activity described by the bereaved. Between these possibilities, of the real, but not imaginal, dyadic relationships of twin babies, and the imaginal but "one-sided" relationships of the living with the dead, there would certainly seem to be a wide middle ground in which relationships between two individual entities have varieties of imaginal content. In other words, there's no forced choice; one need not characterize relationships as either imaginal or real, but not both. To different extents, most real relationships between the living exist primarily, and not solely, in the imaginative and interpretive contents of the mind, and in behaviors and conduct influenced by one's attitude toward one's own mental contents.

I say primarily with emphasis. It is the process of working out whether we have relationships with the dead that has helped me to conclude that some of our most valuable and important relationships are just the ones we endow with loads of imaginal content. I realize that bodies differ, mental capacities and activities differ, and the ways in which we each build up, and feel about, our imaginal relationships qualitatively vary. But whether dead or alive, those we love are those to whom we relate in inevitably imaginal ways. When I say I love my parents, or reflect on my relationship with my spouse, or remember my dead teacher, I don't just recite facts (such as being a beneficiary in my parents' wills), or recall accurately memories 
from the storehouse (that I took a class with my teacher, that there was a ceremony once where I married my spouse). As Sue Campbell says, we endow the facts, experiences, and memories with emotional and interpretive content, and we continue to partake in ongoing interpretive and valuing activity in order to make sense of our relationships, our commitments, and our very selves. We don't just coexist, we build up accounts of our relationships, to ourselves and to others, on which we rely in an ongoing way, so much so that I would argue each of us currently engages in imaginal relationships with the loved ones we hold dear who are not currently in our presence.

We hold them dear by, as Hilde Lindemann says, holding them in personhood in our heads. ${ }^{41}$ I add that the internal and external activities in which we engage in the course of doing so constitute most of the material of real, meaningful relationships. I don't just remember that I have a mother, I talk about her to others; I don't just talk about my mother, I bring forward memories of and observations about her with emotional associations and value-laden interpretations; I don't just wash the dishes when I'm at her house, I wash the dishes because she's my mother. I use her recipe for chocolate cake, and when I share it with others, they just receive it as a recipe, while to me, it's Mom's recipe. Relationships are bred in the heart and in the head, and the relationships that matter to us entail imaginal content. That's why they matter.

However, my account so far leaves open the door to sometimes awkward examples of one-sided relationships, the reality and worth of which we may have reasons not to affirm. I will list four examples, and I invite the reader to consider whether the following relationships are real, or imaginal, or both.

1. Margaret Ray, a woman who reportedly suffered from schizophrenia, was described as "gripped by the fantasy that she was romantically involved with the comedian David Letterman." 42 In the course of her short life, she sent letters to his house, avowed that they were married, "repeatedly broke into his home in New Canaan, Conn., camped out on his tennis court and once stole his Porsche." Letterman read her letters, noting that he could tell when she was adhering to her medication regimen. "When she was on them,... it was like hearing from your aunt," Letterman said in an interview with the New York Times. The reporter adds, "[Letterman] noted that he never mentioned her name on the air, and said that he had great compassion for her, often declining to press criminal charges against her." 43

2. In the semi-autobiographical On the Banks of Plum Creek, Laura Ingalls Wilder recounts the childhood experience of being strongly attached to a rag doll,

\footnotetext{
${ }^{41}$ Hilde Lindemann, Holding and Letting Go: The Social Practice of Personal Identities (Oxford: Oxford University Press, 2014).

42 Frank Bruni, "Behind the Jokes, a Life Of Pain and Delusion; For Letterman Stalker, Mental Illness Was Family Curse and Scarring Legacy," New York Times (November 22, 1998, accessed January 6, 2016). http://www.nytimes.com/1998/11/22/nyregion/behind-jokes-life-pain-delusion-for-lettermanstalker-mental-illness-was-family.html.

43 Ibid.
} 
"darling Charlotte," whom she "loved dearly" and kept clean and safe. ${ }^{44}$ When a houseguest's younger child becomes attached to the doll, her mother presses Laura to let the child keep Charlotte. Laura does so reluctantly, and experiences grief at Charlotte's absence. On a walk some weeks later, she is horrified to find Charlotte in a half-frozen puddle, "drowned," with an eye missing, and otherwise in disrepair. ${ }^{45}$ She breaks Charlotte from the ice, and runs to her mother, who fixes the doll's features and appearance using new material from her rag bag. The two of them agree that "it had been a terrible experience for Charlotte." 46

3. In the movie Cast Away, Tom Hanks plays a character stranded alone on an island. Over the course of years, he falls into the habit of talking to a Wilsonbrand Volleyball, in one scene even responding to imagined criticisms or objections of "Wilson" to his entertainment of plans to commit suicide. In the course of a difficult escape from the island, battered by storms, Wilson is lost, and the main character, anguished upon realizing his loss, repeatedly cries his name. $^{47}$

4. In the course of explaining her account of what it means to "call the fetus into personhood," Hilde Lindemann describes the activities that many pregnant women engage in, arguing that "the mother-to-be treats the fetus as if it had already attained personhood. ${ }^{48}$ It's not uncommon in the course of a pregnancy, for example, for the woman to give the fetus a nickname (my first fetus was Oscar, although the baby turned out to be a girl) and all sorts of other activities, from furnishing a nursery to starting a college fund, are apt to take place in the months before the child is actually born." 49

In all of the above examples, the relationships in which the central agents engage take, as their object, relata that one can aver exist, or at least assemblies of material that bear a relationship to the world of the agent. There is such a person as David Letterman, Laura Ingalls did possess a rag doll, the main character of Castaway drew a face on the surface of Wilson, and Hilde Lindemann was cultivating the growth and eventual personhood of the fetus that she nicknamed Oscar. All four of the agents in the above stories evidently engage in imaginal activities, attributing roles to the objects of their affection. All four of the agents would say, following Yourgrau, that they can name the relata and describe facts about them. Does the intuition to describe one or more of the above examples as imaginal but not real relationships tell against my argument that imaginal relationships with the dead are real, meaningful, valuable relationships?

\footnotetext{
${ }^{44}$ Laura Ingalls Wilder, On the Banks of Plum Creek (London: Puffin Books, 1937/1965), p. 151.

45 Ibid., p. 153.

46 Ibid., p. 154.

47 Tom Hanks, Cast Away (film, performance). Directed by Robert Zemeckis. Hollywood, CA: Twentieth Century Fox, 2000.

48 Hilde Lindemann, "Miscarriage and the Stories we Live By," Journal of Social Philosophy, vol. 46, no. 1, 2015 .

49 Ibid., p. 84.
} 
Although the examples I consider point up the complexities involved in describing the different sorts of relationships that are possible, I find that the dissimilarities provide us with more reason to affirm imaginal relationships with the dead rather than less. Consider the first example. Arguably Ray and Letterman had a real relationship that can be said to be distinct from the imaginal love relationship that Ray maintained. They both undeniably recognized Ray's letters to Letterman as a form of communication, they knew that they shared physical spaces (sometimes simultaneously, usually not), and they each expressed emotional dispositions to see the other in a certain light. The real relationship of Ray and Letterman, sadly, uncomfortably co-existed with the imaginal relationship of romantic love that gripped Ray so powerfully, but was not supported by it. If anything, the real relationship that obtained, between the sometimes-compassionate celebrity and the sometimes-unmedicated housebreaker, persisted despite the imaginal content, rather than because of it.

Case 2 is more challenging, insofar as Laura's attachment to the doll is recognized by her mother as a reason to repair the doll and comfort the girl. Here the imaginal content does seem to contribute to the relational activities in the world, and I have little interest in arguing that Laura didn't really feel fondness. Instead, one could challenge case 2 on the grounds that a rag doll is not really an entity such as Connolly and Yourgrau identified. Without entirely recapping literature on the ship of Theseus, a project out of the scope of the present paper, I could escape the complications of Laura's attachment to Charlotte by arguing that unlike the nonexistent objects the dead may be, Charlotte is an existent bundle of rags and yarns but a conceptual object much more than an existent object. The qualities that made her Charlotte did not turn out to be the particular bits of yarn and rag that made up her features, since Laura's mother reconstituted Charlotte out of new materials. Indeed, if Laura's mother had concluded, that day, that it was necessary to replace $99 \%$ of the doll piece by piece, it is not clear that Laura would have ceased to think of her only doll as the object of her affection. The qualities that made Charlotte a precious being seem to reside in her literal singularity, and of course, Laura's attributions to Charlotte of experienced suffering and returned affection, the entirely fictional product of a lonely girl's wishful thinking. The relationship is more imaginal than real; regard for the rag doll borders on a Pegasuslike notional love.

A similar argument can be made about Wilson in Case 3, and it is just a bit more difficult to do so. Unlike Laura, the castaway is an adult. Unlike Ray, the castaway is not in the grip of a delusion during a difficult period in unmedicated schizophrenia. And unlike a doll of rag-and-yarn, Wilson is distinctive, with a face made of the castaway's own blood, an imprint made so accidentally that it is not easily replicated. What makes the friendship imaginary instead of merely imaginal resides in the material facts of, again, the attribution of the capacity for reciprocity to an object, the entirely fictional product of a lonely man's wishful thinking. The imaginal dialogues that the castaway has with the volleyball are not informed by memories of Wilson's words, mementos, or behaviors of Wilson's, since a nonliving object can offer none of these things. 
Case 4 is the most complex example of the relationship overlapping the real and imaginal, because it is imaginal in ways that inform the real relationship, and yet exceed it. Lindemann wasn't wrong in believing herself pregnant, and the delight she expresses later in the same essay is continuous with the delight she takes in her daughter upon birth; she did not name the resulting daughter Oscar, because the nickname was the product of imaginal work that overran the actualities (in this case, the actuality of her preference for a feminine name in the event she had a girl). The imaginal relationship informs the real relationship and endows it with meaningfulness, even if the imaginal content overruns the facts. The example occurs in an article discussing miscarriage, in which Lindemann notes that "miscarriages often occur because the fetus is so badly deformed that it cannot sustain personhood; the woman's calls to it are then of no avail." ${ }^{50}$ In cases of miscarriage, it is even clearer that the imaginal may overlap and exceed the real at the same time. Some of the expectations and beliefs upheld in relationships- between living entities as well as between the living and their dead-may be dashed, but we would not then be justified in asserting that no real or meaningful relationship exists, or existed. The imaginal relationship is the reason that the real relationship is valuable to the bereaved, because we build up and rest our actions and attitudes on the importance of our memories and thoughts about the dead.

The implications of this account for relationships between the living are complex, since the above amounts to a view that the imaginal content of our most meaningful relationships is partially, and only partially, up to us. One may make commitments and then find it easier to hold them less dear when apart from the person to whom one committed; the conduct that a commitment might inform is meaningful to the person who endows the memory of the commitment with continued imaginal interpretations and import. One may pursue some self-deception that one really made any such commitments, despite the actuality of a living entity who continues to endow the memory of the past commitment with interpretive and imaginal import. And one might be wrong about the actualities; one may endow a shared meal and traded gossip with the imaginal content of friendship when the other diner endows it with no such importance. The importance of imaginal content to actual relationships makes it clearer why injunctions to "get over" someone often fail. One's attachment cannot be ordered away if the imaginal content is the reconstructive process of memory, and if the imaginally informed conduct that provides one with a feeling of closeness to the other is pursuant to the material presence, communications, or wishes of the beloved. Our imaginal content is not entirely up to us, because the memories and actualities of others are not up to us; our relationships and their import exceed what we can control.

\section{Conclusion}

In this essay, I took my project to be one of defending the coherence of a real, meaningful, imaginal relationship with a dead loved one, in part to justify to philosophers the arguments of counselors and bereaved persons that we ought not to

50 Ibid., p. 89. 
pathologize all continuing bonds after bereavement, and in part to provide a basis for arguments in ethics for such activities as forgiving, honoring, or respecting the dead. There may even be ethical and social/political reasons to endorse the maintenance of some relationships with the dead, to the extent that thinking about them conscientiously, cultivating attitudes toward them deliberately, and behaving in the world in the way one chooses to because of relationships with the dead can be sensible and desirable. The value of relationships with the dead better explains why one might carry out someone's last wishes. The real and imaginal also supports why one may check one's conduct against what the departed would wish, because one values the relationship and because the person one is in that relationship is the person one wishes to continue to be. Moral remainders including guilt and resentment also may admit of resolution if we agree that imaginal dialogues with our deceased can admit of discovery, insight, and relationship maintenance. Apologizing to the dead, forgiving the dead, even renouncing the dead, are better supported by appreciation of their relational possibility.

The implications for relationship simpliciter are worth exploring for communities and even nations, although doing so exceeds the bounds of this essay. In Benedict Anderson's classic work on nationalism, Imagined Communities, he says a nation "is an imagined political community, ...imagined because the members of even the smallest nation will never know most of their fellow-members, meet them, or even hear of them, yet in the minds of each lives the image of their communion." ${ }^{51} \mathrm{He}$ adds that indeed any community larger than a village small enough for face-to-face contact of all with all is imagined, "and perhaps even these... communities are to be distinguished, not by their falsity/genuineness, but by the style in which they are imagined," for example, as interconnected, or individualistic, or antagonistic. ${ }^{52}$ Research on bereavement similarly recognize that images and memories of communion between individual others live in the mind, and that a real relationship is both genuine and largely all in one's head. The challenges involved in sorting out what constitutes a meaningful relationship that is worthy of maintenance and predicated on accurate appreciation of the actualities can provoke implications regarding how we ought to live, including how we ought to maintain or end our relationships with the dead, and whether living well with the dead is possible. If the insights of bereaved persons and their counselors can further help the living live well with each other, so much the better.

Open Access This article is distributed under the terms of the Creative Commons Attribution 4.0 International License (http://creativecommons.org/licenses/by/4.0/), which permits unrestricted use, distribution, and reproduction in any medium, provided you give appropriate credit to the original author(s) and the source, provide a link to the Creative Commons license, and indicate if changes were made.

\footnotetext{
51 Benedict Anderson, Imagined Communities: Reflections on the Origin and Spread of Nationalism (London: Verso, 1983), p. 5.

52 Ibid.
} 